\title{
Psicopatía Subclínica, Empatía Emocional y Maltrato Psicológico en la Pareja: Empatía Cero Negativa y Violencia Instrumental-Manipulativa
}

\section{Subclinical Psychopathy, Emotional Empathy, and Psychological Abuse in the Couple: Zero Negative Empathy, and Instrumental-Manipulative Violence}

\author{
José Manuel Pozueco Romero, Juan Manuel Moreno Manso, Macarena Blázquez Alonso \\ y Ma Elena García-Baamonde Sánchez \\ Universidad de Extremadura, España
}

\begin{abstract}
Resumen. En esta revisión analizamos las relaciones entre la psicopatía subclínica, los déficits en empatía cognitiva y emocional y el maltrato psicológico en las relaciones de pareja. Para ello es preciso delimitar el concepto de psicopatía subclínica, así como también la problemática de la violencia psicológica en la pareja, un tipo de violencia que algunos autores han calificado de "invisible", pero que otros autores han hallado manifestaciones o indicadores ostensibles de la misma. Dado que el tipo de maltrato que mayormente perpetran las parejas psicópatas en sus relaciones es de carácter psicológico, éste está relacionado con una violencia instrumental basada en la manipulación y explotación. Los comportamientos que estos sujetos despliegan con sus parejas y/o relaciones íntimas hacen pensar que presentan ciertos déficits emocionales, fundamentalmente una ausencia de empatía afectiva, todo lo cual parece señalar un perfil de personalidades que cosifican a las víctimas sin el mayor reparo, ni escrúpulos, ni remordimientos.

Palabras clave: empatía, maltrato psicológico, psicopatía subclínica, violencia instrumental.
\end{abstract}

\begin{abstract}
In this review we analyze the links between subclinical psychopathy, deficits in cognitive and emotional empathy, and psychological abuse in intimate relationships. This requires to delimit the concept of subclinical psychopathy, as well as the problem of psychological violence in the couple, a kind of violence that some authors have described as "invisible", but others have found overt manifestations or indicators for the same. Because of the type of abuse mostly perpetrated by psychopathic couples in their relationships is a psychological one, this is associated to an instrumental violence based on manipulation and exploitation. Behaviors that these subjects displayed with their partners and/or intimate relationships suggest that they have some emotional deficits, especially a lack of affective empathy, all of which seems to draw a profile of personalities who reify victims without hesitation, no scruples, no regrets.
\end{abstract}

Keywords: empathy, instrumental violence, psychological maltreatment, subclinical psychopathy.

La correspondencia sobre este artículo debe enviarse al primer autor al e-mail de: jmpozueco@hotmail.com 
Psicopatía, narcisismo, maquiavelismo, trastorno límite de la personalidad, autismo y síndrome de Asperger. Las personas que presentan estos cuadros tienen algo en común: la falta de empatía. En algunos casos, esto puede dar lugar a situaciones peligrosas, pero en otros tan sólo significa una forma diferente de interpretar el mundo. No obstante, este trabajo no versa ni sobre la delincuencia violenta ni sobre los trastornos mentales propiamente dichos, sino que vamos a centrar la atención en las manifestaciones subclínicas de tres componentes de lo que se ha denominado como tríada oscura de la personalidad -TRÍOPE-, especialmente sobre los psicópatas subclínicos o integrados.

El rasgo más característico de la psicopatía que numerosas investigaciones han enfatizado es la ausencia de empatía (Cleckley, 1976; Hare, 1993, 2003), que está estrechamente relacionada con otros dos rasgos psicopáticos principales: la incapacidad de amar y la incapacidad de sentir culpabilidad y/o remordimientos (McCord y McCord, 1964). Sin embargo, las teorías que han intentado explicar el modo en cómo esta ausencia de empatía opera en un individuo psicopático en particular no han sido bien entendidas (Mullins-Nelson, Salekin y Leistico, 2006). Debido a que la literatura ofrece numerosas diferencias no sólo sobre la mera definición de empatía sino también sobre la relación entre la empatía cognitiva y la empatía emocional de la psicopatía y sus factores subyacentes (Habel, Kuhn, Salloum, Devos y Schneider, 2002; Kosson, Suchy, Mayer y Libby, 2002), existe una clara necesidad de una mejor comprensión de cómo coexisten todos estos constructos.

La empatía se encuadra dentro de un término más amplio y como componente del mismo: la inteligencia emocional (Vallés, y Vallés, 2000). Entender la empatía, tanto la cognitiva como la emocional o afectiva, puede proporcionarnos una mejor comprensión de la psicopatía. Es importante conocer la relación entre los rasgos psicopáticos y los dos tipos de empatía -la habilidad en la toma de perspectiva (o empatía cognitiva) y la empatía emocional-, ya que se ha hallado que los individuos con puntuaciones altas en psicopatía poseen niveles adecuados de empatía cognitiva, pero muestran, por el contrario, déficits en su capacidad de empatía emocional (Mullins-Nelson et al., 2006). Dicho de otra forma, estas personas tienen la sorprendente habilidad de ver -en un plano meramente intelectual- el punto de vista de los demás, pero no tienen la suficiente o ninguna empatía emocional para -y tampoco la intención de- modificar sus actos y conducirse por la vida de manera apropiada (Pozueco, 2010).

Debido a que existe una gran variedad de beneficios sociales e individuales que se derivan de poseer rasgos de empatía cognitiva y emocional adecuadas, hay muchas implicaciones importantes para tal estudio. En concreto, tal estudio...:

(...) podría ofrecernos una mejor información sobre la relación entre los dos tipos de empatía y la psicopatía, lo cual nos puede proporcionar pistas para la investigación etiológica. También podría tener implicaciones para el concepto de "psicopatía con éxito [integrada/subclínica]". Es decir, el estudio podría arrojar luz sobre el grado en que las personas que puntúan alto en el PPI-SF [un autoinforme abreviado para la evaluación de la psicopatía subclínica] son propensas a involucrarse en conductas ilegales o transgresiones morales, pero que aún permanecen sin ser detectadas por la ley. Además, el estudio actual también podría tener implicaciones respecto a si el tratamiento se puede mejorar mediante entrenamiento en habilidades de empatía cognitiva y afectiva individualmente o en combinación una con otra (Mullins-Nelson et al., 2006, p. 135).

Además de dichas implicaciones, y en relación con la problemática de la violencia en la pareja, la investigación sobre psicopatía y empatía podría, asimismo, ayudarnos a entender parte de la violencia psicológica que perpetran la mayoría de los maltratadores contra sus parejas, especialmente los que tienen un perfil psicopático (Pozueco, Moreno, Blázquez y García-Baamonde, en prensa) y que se diferencian en varios aspectos de aquellos maltratadores con un perfil psicopatológico y más claramente antisocial (Pozueco y Moreno, 2013; Spidel et al., 2007). 
En suma, y teniendo en cuenta todas las implicaciones señaladas, el objetivo de la presente revisión teórica es ofrecer una panorámica actualizada sobre el estado de la cuestión y los estudios de investigación que han explorado las relaciones entre los rasgos psicopáticos, los déficits en los dos tipos de empatía -cognitiva y emocional- y la violencia psicológica e instrumental en las relaciones de pareja. Centrándonos en el concepto de psicopatía subclínica o integrada, una de las conclusiones fundamentales que podríamos extraer de la revisión de la literatura científica aquí realizada descansa en el hecho de que las dinámicas relacionales de pareja de los y las psicópatas integrados/as generan un ambiente turbio, desestabilizador y volátil (Jonason, Valentine, Li y Harbeson, 2011), caracterizado fundamentalmente por mentiras, seducciones superficiales, manipulaciones y patrones de interacción coactiva de diversa índole, todo lo cual evidencia que las relaciones íntimas con psicópatas integrados/as, a pesar de su encanto y apariencia superficiales, se caracterizan por un tipo de violencia mayormente de carácter psicológico y donde la ausencia de empatía cobra un papel especial, siendo fuente de una ostensible crueldad e insensibilidad y generando un sufrimiento inenarrable por y para las víctimas (Pozueco, Moreno, Blázquez y García-Baamonde, 2013).

\section{La psicopatía subclínica y el maltrato psicológico en las relaciones íntimas}

\section{El perfil psicosocial de los psicópatas subclínicos, integrados o no criminales}

La psicopatía sigue estando rodeada de un conjunto de variadas polémicas desde hace ya más de 200 años de historia que tiene el término (Pozueco, Romero y Casas, 2011). Una de ellas es la referente a la diferencia entre ser psicópata -es decir, reunir las características de la psicopatía como forma de ser y estilo de vida- y parecerlo -es decir, desplegar ciertos rasgos psicopáticos aislados y en concretas situaciones- (Pozueco, 2010). Así, algunas personas no son psicópatas, pero lo parecen, polémica distinción que ha sido abordada ampliamente por Marietán (2011).

Pero la polémica más ácida y perdurable en torno al concepto de psicopatía ha sido la referente a la constante y errónea equiparación de ésta con el trastorno antisocial de la personalidad -TAP- (Pozueco, 2011; Pozueco et al., 2011). A pesar de que numerosas investigaciones han reiterado y subrayado (a) que TAP y psicopatía no son entidades equiparables (Hare, Hart y Harpur, 1991), (b) que la conducta antisocial no es una característica esencial y/o definitoria de la psicopatía (Cleckley, 1976), (c) que ni todos los delincuentes son psicópatas ni todos los psicópatas son delincuentes (Raine y Sanmartín, 2000), y (d) que la conducta criminal/delictiva tampoco es un componente central ni esencial de la psicopatía (Skeem y Cooke, 2010), lo cierto es que actualmente siguen habiendo autores que no reparan en estos importantes y necesarios matices. Es preciso volver a recordar, como recientemente lo han hecho varios estudios, que la psicopatía no es un diagnóstico clínico del DSMIV-TR (Marsh, 2013), independientemente de que algunas características de la psicopatía -sobre todo las relacionadas con la vertiente conductual- estén incorporadas dentro del Eje II para el diagnóstico del TAP (Lynam y Vachon, 2012). De hecho, recientemente se han propuesto varias sugerencias para la actualización del DSM5 con objeto de reflejar las conceptualizaciones actuales de la psicopatía tanto en niños (Frick y Moffitt, 2010) como en adultos (Skodol et al., 2011). El problema de estas sugerencias estriba en que se siguen equiparando psicopatía y TAP, y ya hemos comentado -de acuerdo a los estudios mencionados- que tal equiparación es incorrecta por la sencilla razón de que la psicopatía no es un trastorno mental y el TAP sí lo es por estar ubicado en las nosologías psiquiátricas.

Con respecto al TAP y a la polémica del parecer psicópata, es preciso insistir en que el TAP es un concepto que no hace otra cosa sino caracterizar al delincuente común o habitual (Pozueco, 2011), y a este respecto, en una línea similar, Garrido (1994) realizaba una serie de matizaciones y sugerencias de especial relevancia que vienen aquí a colación: 
La idea central es que hay que cortar la definición en los criterios de Cleckley; el resto de sujetos no hacen sino engrosar la lista de delincuentes o de sujetos normales, con las peculiaridades propias de cada uno de ellos. Es, precisamente, el problema de la definición de la personalidad antisocial del DSM-IV: es tan amplia que abarca a todo delincuente con una carrera delictiva amplia, iniciada en la pre-adolescencia (Garrido, 1994, p. 69).

Puestos de relieve estos matices y recogiendo la sugerencia de Garrido (1994) de «cortar la definición en los criterios de Cleckley», es de rigor recordar que la psicopatía fue originalmente descrita en detalles considerables por Cleckley (1976), en su obra The Mask of Sanity, como un síndrome -que no trastorno- atípico de la personalidad que comprende componentes interpersonales, afectivos, conductuales y, en algunos casos, componentes potencialmente antisociales. Así, en el plano interpersonal, los psicópatas han sido descritos por rasgos tales como encanto superficial, inteligentes, egocentrismo y manipulación. En el plano efectivo-emocional, los rasgos psicopáticos más pronunciados son la ausencia de empatía, la ausencia de remordimientos y de sentimientos de culpabilidad, y un conjunto de afectos superficiales y poco profundos. En el plano conductual, los psicópatas son descritos como impulsivos, irresponsables y buscadores de sensaciones. Finalmente, algunos autores han venido considerando que otros componentes y/o rasgos conductuales del síndrome incluyen antisocialidad y/o transgresiones morales (Hare, 2003), si bien hay que precisar que estos rasgos concretos hacen referencia expresa a un «estilo de vida crónicamente inestable y antisocial, y desviación social» (Hare, 2003, p. 76), y ya hemos dicho que no todo psicópata ni es delincuente ni lleva un estilo de vida crónicamente antisocial, ni tampoco forman parte exclusiva de fenómenos de desviación social, sino que muchos de ellos se encuentran perfectamente integrados entre nosotros, al menos en apariencias (Pozueco, 2010), y que sólo pasan a la categoría de criminales/delincuentes cuando son descubiertos por la policía y procesados por la justicia por la concreta comisión de un delito o delitos -sean del tipo que sean: robos, estafas, fraudes a hacienda, agresiones sexuales, homicidios, etc.- (Pozueco, 2011).

Las diferencias entre la psicopatía subclínica y la psicopatía criminal son evidentes, fundamentalmente, en su vertiente conductual. Los dos autores que principalmente han sido los promotores de ambos conceptos de psicopatía son Cleckley y Hare. A modo comparativo, en la Tabla 1 se exponen los rasgos psicopáticos según la perspectiva de ambos autores.

Como decíamos antes, el mayor problema con que se ha venido encontrando el constructo de psicopatía es el de haber sido constante y prejuiciosamente relacionado tanto con la conducta antisocial como con la conducta criminal/delictiva (Pozueco et al., 2013), muy a pesar de que Cleckley (1976) subrayara que la conducta antisocial no es un síntoma esencial del síndrome de la psicopatía, entendiendo lo de síndrome, sencillamente, como conjunto de síntomas, y no como sinónimo de cuadro psicopatológico, ya que la psicopatía también se caracteriza por la total ausencia de cualquier manifestación psicopatológica -por ejemplo, véanse los ítems 2 y 3 del listado de Cleckley en la Tabla 1.

Finalmente, desde el punto de vista subclínico no se estudia la psicopatía como una categoría clínica artificial, sino como un rasgo general de la personalidad en la población general o civil (Benning, Patrick, Blonigen, Hicks y Iacono, 2005; Hall y Benning, 2006; Lynam y Derefinko, 2006), y no en la población clínica ni en la jurídico-forense. En este sentido, la evidencia reciente sugiere que la psicopatía no es taxonómica en su estructura sino dimensional: los rasgos psicopáticos parecen estar distribuidos de forma continua en la población y pueden ser más fiable y válidamente evaluados cuando son abordados como un continuo en vez de como una variable discreta (Edens, Marcus, Lilienfeld y Poythress, 2006; Guay, Ruscio, Knight y Hare, 2007; Kotov et al., 2011). Esto es importante porque sugiere que la información sobre la psicopatía se puede extraer tanto de muestras con diagnóstico clínico (Cooke, Michie y Hart, 2006) como de muestras de la comunidad (Malterer, Lilienfeld, Neumann y Newman, 2010).

Puesto de manifiesto todo este planteamiento, el estudio de los psicópatas integrados o subclínicos es sen- 
Tabla 1. Los rasgos principales de la psicopatía según las perspectivas clínica y criminológico-forense

\section{PSICÓPATA SUBCLÍNICO}

(Hervey Milton Cleckley, 1976)

\section{PSICÓPATA CRIMINAL}

(Robert D. Hare, 2003)
1. Encanto superficial y notable inteligencia

2. Ausencia de alucinaciones y otros signos de pensamiento irracional.

3. Ausencia de nerviosismo y/o de manifestaciones psiconeuróticas.

4. Indigno de confianza.

5. Falsedad o insinceridad.

6. Incapacidad para experimentar remordimiento o vergüenza.

7. Conducta antisocial sin aparente justificación.

8. Falta de juicio y dificultades para aprender de la experiencia.

9. Egocentrismo patológico e incapacidad para amar.

10. Pobres reacciones afectivas.

11. Pérdida específica de intuición.

12. Insensibilidad en las relaciones interpersonales ordinarias.

13. Conducta exagerada y desagradable bajo el consumo de alcohol y, a veces, sin él.

14. Amenazas de suicidio constantes, pero raramente consumadas.

15. Vida sexual impersonal, frívola y poco estable.

16. Incapacidad para seguir cualquier plan de vida.
1. Locuacidad y encanto superficial.

2. Sentido de autovaloración grandilocuente.

3. Necesidad de estimulación y propensión al aburrimiento.

4. Mentira patológica.

5. Estafador-engañador y manipulador.

6. Ausencia de remordimientos y de sentimientos de culpabilidad.

7. Afecto superficial.

8. Insensibilidad, crueldad y falta de empatía.

9. Estilo de vida parásito.

10. Pobre control de la conducta.

11. Conducta sexual promiscua.

12. Problemas de conducta en la infancia.

13. Incapacidad para establecer metas realistas a largo plazo y aprender de la experiencia.

14. Impulsividad.

15. Irresponsabilidad.

16. Incapacidad para aceptar la responsabilidad de sus actos.

17. Relaciones maritales frecuentes y breves.

18. Delincuencia juvenil.

19. Revocación de libertad condicional.

20. Versatilidad criminal/delictiva.

cillo de entender: se trata de personas que cumplen los criterios de la psicopatía y que no se involucran en conductas delictivas; tema aparte es que sean potencialmente delincuentes (Pozueco et al., 2013).

\section{El maltrato psicológico en las relaciones de pareja: Una violencia invisible, pero con indicadores detectables}

«El daño psíquico conforma una de las secuelas de la victimación de un delito» (Arce, Fariña, Carballal y Novo, 2009, p. 242). Dicho daño psíquico, según estos mismos autores, también se denomina como huella psicológica, y ésta es especialmente incidente en la violencia perpetrada en el ámbito de la pareja y/o de las relaciones íntimas. Las principales organizaciones internacionales con competencias en salud consideran la violencia en la pareja como un fenómeno que constituye un problema de salud mundial con serias repercusiones tanto en el ámbito físico como mental de las víctimas (Blázquez y Moreno, 2008b; Blázquez, Moreno y GarcíaBaamonde, 2009b).

Pero hay varios problemas que aún persisten en el estudio de la violencia en la pareja, siendo los más habituales los referidos al género, al tipo de maltrato perpetrado y a las tipologías de agresores/as. Es importante subrayar y matizar, aunque sea de manera breve, estas problemáticas sobre todo en lo concerniente al tema principal de estudio en el que aquí nos centramos, ya que a los tópicos y/o prejuicios existentes en torno al concepto de psicopatía suelen unirse los referentes al ámbito de las relaciones de pareja.

La violencia contra la pareja es un problema complejo de analizar, que tiene un impacto directo sobre la salud física y psicológica de quien la padece, y en el que víctimas y agresores son personas muy heterogéneas (Echeburúa, Amor, Loinaz y De Corral, 2010; Fariña, Arce y Buela-Casal, 2009; Loinaz, Echeburúa, OrtizTallo y Amor, 2012).

En cuanto a la problemática sobre la variable género, y aunque habitualmente la violencia contra la pareja tiende a asociarse con la violencia ejercida del varón hacia la mujer, Blázquez, Moreno y García-Baamonde (2010) nos informan de que son varios los estudios de corte sociológico, clínico y social que consideran equiparable la frecuencia con la que varones y mujeres ejercen las distintas formas de violencia. No obstante, las 
secuelas de la violencia en la pareja suelen ser siempre más devastadoras en el caso de la mujer, fundamentalmente por la diferencia que existe entre ambos sexos en cuanto a la complexión y fuerza física (Blázquez et al., 2009b). Por ello, existe mayor dificultad a la hora observar en los varones todo síntoma que registre los lamentables efectos de lo que Walker (2000) denominó como síndrome de la mujer maltratada y que describe conductas como la inhibición, el aislamiento y el fatalismo de la víctima. En general, podemos definir la violencia en la pareja como...:

(...) la relación de abuso que se establece dentro de una pareja, ya sea que quienes la conforman vivan o no juntos, pudiendo estar su vínculo enmarcado por diversos tipos de compromiso, formales o personales. Esto incluye la relación conyugal, relaciones de convivencia, relaciones de noviazgo y las relaciones de la ex-pareja (Blázquez y Moreno, 2008a, p. 480).

Por tanto, la violencia contra la pareja ocurre en una variedad de relaciones íntimas: matrimonios, parejas en convivencia o sin ella, o ex-parejas (Dutton, 2006).

Respecto a la problemática sobre las tipologías de maltratadores, cada vez se hace más evidente en la actualidad que los agresores contra la pareja no constituyen un grupo homogéneo (Loinaz, Echeburúa y Torrubia, 2010). En este sentido, se subraya que quizá los programas de intervención sean inapropiados para una proporción sustancial de maltratadores debido a la heterogeneidad de los agresores como grupo (Bowen, Gilchrist y Beech, 2008; Cavanaugh y Gelles, 2005).

Como señalan Amor, Echeburúa y Loinaz (2009), los distintos estudios realizados hasta la fecha proponen la existencia de dos e incluso cuatro subtipos de agresores, diferenciables según la gravedad y extensión de la violencia, las alteraciones psicopatológicas o de personalidad, el apego o la ira. La tipología más citada es la de Holtzworth-Munroe y Stuart (1994), quienes propusieron la existencia de tres dimensiones: el funcionamiento psicológico, la extensión y la gravedad de la violencia. Junto a éstas, su modelo del desarrollo resaltaba variables históricas -factores prenatales y genéticos, experiencias de la infancia- y actuales -impulsividad, habilidades sociales, actitudes hacia las mujeres y sobre la violencia, tipo de apego-como posibles factores de riesgo. Así, estos autores hallaron tres tipos de agresores: a) limitados al ámbito familiar (FO); b) borderline/disfóricos (BD); y c) violentos en general/antisociales (GVA). En un estudio posterior, HoltzworthMunroe, Meehan, Herron, Rehman y Stuart (2000) describieron un cuarto tipo, el denominado antisocial de nivel bajo (LLA), cuyas características se ubicarían entre el tipo FO y el GVA.

En España, un análisis de conglomerados realizado sobre sujetos encarcelados ha permitido establecer dos tipos diferenciados de agresores contra la pareja:

El primero, al que podemos denominar «violentos con la pareja/estables emocionalmente/integrados socialmente», se caracteriza por una violencia limitada al ámbito de la pareja; los sujetos tienen mayor autoestima, muestran menos distorsiones cognitivas, abusan menos del alcohol y de las drogas, tienen mayor control de su ira y cuentan con menos antecedentes penales. El segundo, que se puede calificar como «violentos generalizados/poco estables emocionalmente/no integrados socialmente», presenta un perfil caracterizado por la extensión de la violencia más allá del entorno familiar, así como por alteraciones de la personalidad y abuso de alcohol/drogas, mayor presencia de distorsiones cognitivas y más antecedentes penales. En definitiva, el clúster 2 se caracteriza por una violencia más general y peligrosa, mientras que la del clúster 1 se precipita más por factores situacionales -estrés, mala relación de pareja, consumo de alcohol, etcétera- (Loinaz et al., 2010, p. 110).

De todos estos tipos de agresores de pareja nos interesa aquí el maltratador psicopático, que algunos estudios han equiparado con el maltratador violento en general/antisocial (Echeburúa y Fernández-Montalvo, 2007), habiéndose hallado en ambos tipos de agresores una mayor prevalencia en relación a las distorsiones 
cognitivas. En cualquier caso, es importante matizar que los maltratadores psicópatas y los maltratadores antisociales/generalmente violentos, aunque coinciden en algunos rasgos -fundamentalmente en los de corte conductual-, presentan perfiles de personalidad y emociones distintivos (Pozueco et al., en prensa; Spidel et al., 2007) que es preciso tener en cuenta dadas las serias implicaciones tanto a nivel clínico como a nivel políticosocial y legal (Huss y Langhinrichsen-Rohling, 2000, 2006).

Finalmente, en cuanto a la problemática sobre el tipo de maltrato perpetrado, hay que recordar que «la mayoría de los estudios en torno a la violencia "conyugal" presentan un marcado interés por la dimensión física del maltrato, ignorando el maltrato psicológico a pesar de su elevada incidencia y graves repercusiones en la víctima» (Blázquez, Moreno y García-Baamonde, 2009a, p. 692). Diferentes estudios epidemiológicos consideran el maltrato psicológico como la forma de agresión de mayor incidencia en las relaciones de pareja, y proporcionan información reveladora al respecto. A pesar de tales evidencias, el maltrato físico se constituye como el principal objeto de análisis en las relaciones de pareja, frente a la olvidada figura del maltrato psicológico (Blázquez et al., 2010).

Lo que no hay que olvidar es que «la violencia en la pareja suele manifestarse, en primer lugar, como agresión verbal en sus formas más encubiertas» (Blázquez y Moreno, 2008a, p. 484). La violencia psíquica ha recibido varias denominaciones, entre las que cabe destacar aquí la de violencia invisible (Asensi, 2008), de ahí lo de "formas más encubiertas". En otro trabajo describimos ampliamente esta cuestión (Pozueco et al., 2013), donde subrayábamos que el maltrato psicológico se caracteriza tanto por una serie de factores y subfactores que configuran las manifestaciones o indicadores de maltrato psicológico -IMP- (Taverniers, 2001) como por un conjunto de mecanismos encubiertos y manifiestos de abuso emocional en los que Asensi (2008) englobó los IMP señalados por Taverniers (2001). A modo de resumen, en la Tabla 2 y en la Tabla 3 se recogen, respectivamente, dichos IMP y mecanismos de abuso emocional.

Tabla 2. Los IMP, según Taverniers (2001)

\begin{tabular}{|c|c|}
\hline FACTORES & SUBFACTORES \\
\hline 1. DESVALORIZACIÓN & $\begin{array}{l}\text { 1. Ridiculización } \\
\text { 2. Descalificaciones } \\
\text { 3.Trivializaciones } \\
\text { 4. Oposiciones } \\
\text { 5. Desprecio }\end{array}$ \\
\hline 2. HOSTILIDAD & $\begin{array}{l}\text { 1. Reproches } \\
\text { 2. Insultos } \\
\text { 3. Amenazas }\end{array}$ \\
\hline 3. INDIFERENCIA & $\begin{array}{l}\text { 1. Falta de empatía y de apoyo } \\
\text { 2. Monopolización }\end{array}$ \\
\hline 4. INTIMIDACIÓN & $\begin{array}{l}\text { 1. Juzgar, criticar, corregir, etc. } \\
\text { 2. Posturas y gestos amenazantes } \\
\text { 3. Conductas destructivas }\end{array}$ \\
\hline 5. IMPOSICIÓN DE CONDUCTAS & $\begin{array}{l}\text { 1. Bloqueo social } \\
\text { 2. Órdenes } \\
\text { 3. Desviaciones } \\
\text { 4. Insistencia abusiva } \\
\text { 5. Invasiones en la privacidad } \\
\text { 6. Sabotajes }\end{array}$ \\
\hline 6. CULPABILIZACIÓN & $\begin{array}{l}\text { 1. Acusaciones } \\
\text { 2. Gaslighting (luz de gas) } \\
\text { 3. Negación / desmentida }\end{array}$ \\
\hline 7. BONDAD APARENTE & 1. Manipulación de la realidad \\
\hline
\end{tabular}


Tabla 3. Mecanismos encubiertos y manifiestos de abuso emocional, según Asensi (2008)

MECANISMOS ENCUBIERTOS

- Descalificar

- Negar

- Proyectar / acusar

- Desmentir el abuso por parte del abusador
- Connotar negativamente

- Amenazar sutilmente con abandono físico o emocional

- Abandonar en realidad, física o emocionalmente

\section{MECANISMOS MANIFIESTOS}

- Despreciar

- Gritar

- Insultar o expresar malas palabras

- Criticar

- Ordenar

- Mostrar malhumor

- Negar y retener afecto

- Ignorar

- Aislar a la víctima de sus familiares y amigos

- Monitorear el tiempo y las actividades de la víctima

- Intentar restringir recursos (finanzas, teléfono, etc.)

- Interferir con oportunidades (trabajo, atención médica, educación, etc.)

- Acusar a la víctima de estar involucrada en conductas repetidas e intencionalmente dañinas
- Tirar objetos, no necesariamente hacia la víctima

- Golpear objetos, dar portazos

- Ridiculizar a la víctima

- Expresar asco hacia la víctima

- Amenazar con dejarla (física o emocionalmente)

- Expresar celos excesivos

- Amenazar la vida, las mascotas, la propiedad o la familia de la víctima

- Exponer a la víctima a escenas de abuso hacia sus hijos, mascotas, padres, etc.

- Obligar a la víctima a que realice actividades ilegales

- Provocar a la víctima para que se defienda

\section{Psicopatía y empatía}

\section{Los psicópatas disponen de empatía cognitiva, pero no de empatía emocional}

El éxito en la interacción social es un componente vital del mundo moderno, con nuestras relaciones, y muchos otros aspectos importantes dependen de ello. Sin embargo, muchos de nosotros solemos encontrarnos con personas con «rasgos de personalidad socialmente aversivos» (Lee y Ashton, 2005, p. 1572). La psicopatía subclínica y el maquiavelismo reúnen estos criterios o rasgos; si bien ambos constructos se asemejan mucho (Fehr, Samsom y Paulhus, 1992), aunque en última instancia son distinguibles y también lo son con respecto al tercer componente de la TRÍOPE, el narcisismo (Paulhus y Williams, 2002; Vernon, Villani, Vickers y Harris, 2008), lo cierto es que «los constructos de personalidad "oscuros" se caracterizan por el afecto superficial, la crueldad, la ausencia de sentimientos de culpabilidad, la manipulación y el encanto superficial» (Ali y Chamorro-Premuzic, 2010a, p. 169).

Teniendo en cuenta el impacto negativo que los individuos con rasgos psicopáticos y maquiavélicos pueden tener en los demás (McHoskey, Worzel y Szyarto, 1998), se intuye que tanto la psicopatía como el maquiavelismo estarían asociados a una deficiencia en la empatía, que es esencialmente la capacidad de comprender y compartir la experiencia mental de otra persona. En general, los investigadores coinciden en que la empatía tiene un componente afectivo y un componente cognitivo (Lawrence, Shaw, Baker, Baron-Cohen y David, 2004). Así, la empatía afectivalemocional puede ser definida como la capacidad de experimentar las emociones de los demás, mientras que la empatía cognitiva, a menudo referida como Teoría de la Mente -TdM-, se conceptualiza como la capacidad de comprender e inferir los afectos y las experiencias emocionales de los demás (Jolliffe y Farrington, 2004).

Como era de esperar, varios estudios de investigación señalan que la psicopatía subclínica y el maquiavelismo correlacionan negativamente con la empatía en general (Andrew, Cooke y Muncer, 2008; Mahmut, Homewood y Stevenson, 2008), y, de acuerdo con los resultados en muestras clínicas (Blair, 2005), la investigación no clínica o subclínica también sugiere que la psicopatía y el maquiavelismo pueden estar relacionados 
con una respuesta empática inadecuada a los estímulos afectivos, que es la empatía emocional o afectiva (Ali, Amorin y Chamorro-Premuzic, 2009).

Quienes obtienen puntuaciones altas en psicopatía y maquiavelismo tienen éxito en la manipulación y el engaño (Austin, Farrelly, Black y Moore, 2007; Hare, 1993), lo que indicaría que algunas personas tienen cierta habilidad en empatía cognitiva. La investigación con muestras clínicas en relación a la TdM ha hallado que los individuos con psicopatía no tienen un déficit cognitivo en comparación con los sujetos controles no psicopáticos (Richell, Mitchell, Newman, Leonard, Baron-Cohen y Blair, 2003). Con respecto al maquiavelismo, la investigación demuestra que se asocia con la incapacidad de comprender las emociones y el empobrecimiento emocional en general (Wastell y Booth, 2003). En un estudio con una muestra de adultos que investigó el maquiavelismo directamente en relación con la TdM, Paal y Bereczkei (2007) no hallaron una relación significativa entre el maquiavelismo y la empatía cognitiva.

Por su parte, la aplicación de la TdM en relación al maquiavelismo y la psicopatía en muestras no clínicas es controvertida, y no es sencilla de entender. De hecho, hay pocos estudios que examinen específicamente la relación entre la psicopatía y la empatía (Kirsch y Becker, 2007). Según algunos autores, la investigación de la TdM sobre los rasgos aversivos u "oscuros" -los de la TRÍOPE- es importante porque es posible que los individuos con rasgos psicopáticos y maquiavélicos, más que no estar dispuestos a empatizar, puede que en realidad tengan dificultades en empatía cognitiva y, por lo tanto, es posible que «no puedan ponerse de manera suficiente en la mente de los demás» (Baron-Cohen, Wheelwright, Hill, Raste y Plumb, 2001, p. 241).

Dejando a un lado la enrevesada TdM, lo cierto es que, como señalan algunos autores, los resultados contradictorios en esta área pueden deberse a que la mayoría de la literatura se basa principalmente en medidas de auto-informe de los déficits de empatía global, «por lo que es imposible determinar si la falta de empatía en la psicopatía se debe a déficits en la empatía cognitiva, en la empatía afectiva, o en ambos» (Kirsch y Becker, 2007, p. 916). Ali et al. (2009) hallaron déficits de empatía afectiva en la psicopatía no clínica y en el maquiavelismo, y en el estudio de Ali y Chamorro-Premuzic (2010a) también se hallaron déficits en empatía cognitiva en ambos componentes de la TRÍOPE.

Finalmente, más clara parece la evidencia hallada en las investigaciones que han estudiado la teoría de la ausencia de miedo del psicópata en relación con la ausencia de empatía, evidencia que también enlaza con otro aspecto que posteriormente abordaremos: la agresión básicamente instrumental de los psicópatas. Así, en un reciente artículo se resumen el estado de la cuestión sobre este concreto particular argumentando lo siguiente:

La evidencia acumulada con muestras de psicópatas apoya la conclusión de que el miedo es una emoción cualitativamente distinta de otras emociones como, por ejemplo, la ira [...]. Los déficits similares de los psicópatas en experimentar miedo y en reconocer el miedo de los demás añade apoyo a la noción de que la empatía hacia los estados afectivos resulta de representaciones compartidas respecto a las experiencias personales y vicarias del miedo, las cuales son consistentes con las teorías basadas en la simulación de la empatía. Estas conclusiones pueden ser útiles no sólo en la promoción de los estudios neurocientíficos de la emoción, sino también en el desarrollo de una mejor comprensión de la naturaleza fundamental de la psicopatía, la empatía y la agresión (Marsh, 2013, pp. 9-10).

\section{Los psicópatas y la empatía cero negativa: Ni sienten ni padecen}

Simon Baron-Cohen es uno de los autores más destacados en los estudios sobre la TdM. Especialmente, nos interesa aquí el último libro publicado por Baron-Cohen (2011), titulado Cero Grados de Empatía: Una Nueva Teoría de la Crueldad Humana. El autor basa parte de su interés en la materia, según cuenta como anécdota, tras recordar que su padre, cuando él tenía 7 años, le explicó cómo los nazis habían convertido a judíos en portalámparas. Pero la "perversión" de tratar a los humanos como objetos - cosificarlos, tratarlos como a cosas- 
no fue sólo un acto de los nazis. En su libro, Baron-Cohen (2011) escruta los pormenores de este comportamiento que deriva en tratar a los humanos con crueldad, entendida esta última no desde el punto de vista sensacionalista y mediático del "mal", sino desde la ausencia de empatía. ¿Cuáles son las razones que incitan esta falta de empatía que alimenta, sin duda, la crueldad de unos contra otros?

Baron-Cohen (2011) define la empatía como una «capacidad de identificar lo que otra persona piensa o siente y responder ante sus pensamientos y sentimientos con una emoción adecuada» (p. 11). Este autor divide el mecanismo de la empatización en seis niveles, sosteniendo que quien se sitúa en el nivel 6 es el tipo opuesto al cero-positivo/negativo, es decir, una persona muy intuitiva, conectada para sentir los sentimientos de los demás, leer la mente de los demás y anticipar el desarrollo de un argumento en el ámbito social.

Asimismo explica que cuando una persona está centrada en sus propios intereses y no es capaz de tratar a los demás como si fueran personas, sino que las ve como si fuesen objetos, carece de empatía o su empatía es cero. En esos casos extremos, la erosión de la empatía puede dar lugar a personas crueles con los demás. Son algunos tipos de personas con una empatía que el autor denomina cero-negativa, y establece tres tipos de ceronegativos: el tipo B con trastorno límite de la personalidad, el tipo $\mathrm{P}$ con psicopatía y el tipo $\mathrm{N}$ con trastorno narcisista de la personalidad. La denominada empatía cero-positiva la otorga, por ejemplo, a las personas con síndrome de Asperger.

La empatía cero negativa se caracteriza por aquella ausencia de empatía que facilita la cosificación de los demás, es decir, la deshumanización de las personas y el empleo de la crueldad con las mismas, como si fueran objetos/cosas (Baron-Cohen, 2011). Es en este sentido en el que se dice que los psicópatas ni sienten ni padecen (Pozueco, 2010).

Como decíamos antes, las personalidades narcisistas, borderline y psicopáticas se caracterizan por carecer de empatía afectiva -la capacidad de sentir los sentimientos de los demás-. El novedoso paradigma de BaronCohen (2011) clasifica a estos tipos de personalidad como de "cero-negativo", argumentando que una cantidad cero de empatía afectiva es una condición negativa debido a que la capacidad de auto-regular la forma en que esos tres tipos de personalidades tratan a los demás está comprometida de manera significativa. Por el contrario, define a las personas con síndrome de Asperger o autismo clásico como "cero-positivo". Al igual que el tipo cero-negativo, estas personas no sólo carecen de empatía afectiva, sino que además marcan cero en empatía cognitiva -es decir, en pensar en los pensamientos de los demás-.

Por tanto, hay diferencias esenciales entre las personalidades psicopáticas, narcisistas y límites con respecto a las personas con síndrome de Asperger, y la diferencia más fundamental estriba en que las tres primeras sólo carecen de empatía emocional, mientras que las personas con Asperger carecen tanto de empatía emocional como cognitiva. Esto remite a la idea de que, en el concreto caso de análisis que nos ocupa, «los psicópatas se saben la letra, pero no la música» de las emociones (Johns y Quay, 1962, p. 217), de ahí que estos sujetos sólo tengan el tipo de empatía cognitiva, lo que implica que saben lo que tienen que decir a los demás y lo que éstos quieren oír, pero en absoluto lo sienten (Pozueco, 2010). Podemos llegar a entender de forma más clara todas estas diferencias realizando una comparación entre las características típicas de las personas con síndrome de Asperger y las características de la psicopatía subclínica. En la Tabla 4 realizamos una síntesis comparativa.

Para Baron-Cohen (2011), los psicópatas tienen una empatía cero-negativa. Para este autor, los psicópatas comparten la misma preocupación y única por uno mismo que los borderlines, pero...:

(...) en el caso de los psicópatas hay una voluntad de hacer todo lo que sea necesario para satisfacer sus deseos. Esto puede tomar la forma de una reacción de gatillo violenta ante la más mínima cosa que les frustre. O puede tomar una forma fría, la crueldad calculada. A veces la agresión sin sentido no es provocada por una amenaza percibida, sino por la necesidad de dominar, para conseguir lo que uno quiere, un desapego completo de los sentimientos de otra persona, e incluso un poco de placer al ver a alguien sufrir (Baron-Cohen, 2011, p. 43). 
Tabla 4. Comparación diferencial entre las características típicas de las personas con síndrome de Asperger y las personas con psicopatía subclínica

\section{SÍNDROME DE ASPERGER \\ (empatía cero-positiva) \\ (Baron-Cohen, 2011)}

\section{PSICÓPATAS INTEGRADOS \\ (empatía cero-negativa) \\ (varios autores)}

1. Muestran hipoactividad en todas las áreas cerebrales del circuito de la empatía, lo que parece generarles dificultades y/o problemas para entender y leer la mente de los demás y también para entender su propia mente -falta de palabras para describir correctamente las emociones o alexitimia-.

2. Se muestran confusos en situaciones sociales, sin saber cómo reaccionar por falta de recursos mentales y habilidades sociales.

3. No se relacionan con la gente.

4. Pueden presentar una baja capacidad para mantener una conversación simple.

5. Tienen una sensibilidad extraordinaria y precisión para percatarse de algunos patrones que ocurren en la vida diaria. Son capaces de darse cuenta de que algunas secuencias de datos que ya se han producido anteriormente y descubrir, por tanto, el patrón o la regla que sigue. Esta supercapacidad de sistematizar puede llegar a extremos como es el caso de Daniel Tammet que ha llegado a ser campeón de Europa en la destreza de memorizar el número pi hasta 22.514 decimales, siendo también capaz de multiplicar dos números de seis cifras a la misma velocidad que una calculadora.

6. Presentan mentes increíblemente precisas y exactas. Su cerebro procesa la información de una forma tan especial que pueden llegar a ser talentos en una disciplina.
1. Todos los estudios neurobiológicos realizados sobre la psicopatía hasta la fecha no son concluyentes: la mayoría de ellos no han empleado el PCL-R -sino los criterios del TAP- para evaluar a los psicópatas encarcelados de sus muestras, y los errores metodológi-' cos de muchos estudios son muy serios (Pozueco, 2011).

2. Son carismáticos, superficiales, con algunas respuestas relativamente ingeniosas, etc., lo que les facilita integrarse entre los demás y desenvolverse sin mayores problemas (Cleckley, 1976; Hare, 1993).

3. Necesitan relacionarse con los demás en aras de conseguir sus fines a través de los medios que sean precisos (Pozueco, 2010). No tiene sentido la manipulación que perpetran si no hay nadie sobre quien ejercerla (Black, 2013; Grieve y Mahar, 2010).

4. Son personas locuaces -de labia fácil-, que "se van por las ramas" y/o cambian las conversaciones cuando no les interesan o les comprometen (Hare, 1993), pudiendo llegar a mantener conversaciones relativamente complejas a través del uso de tecnicismos que desconocen (Pozueco, 2010) pero que forman parte del repertorio típico del lenguaje superficial que les caracteriza (Cleckley, 1976; Hare, 1993).

5. La pérdida específica de intuición es una de sus características más notables (Cleckley, 1976), por más que algunos autores hayan querido retratarlos como muy inteligentes. Parece ser que tienen una habilidad extraordinaria en detectar los "puntos débiles" de los demás (Hare, 1993), lo que sólo les interesa para obtener sus propios beneficios, pero no es menos cierto que esos "puntos débiles" de los demás los suelen generar los propios psicópatas en sus víctimas a través de un insidioso ciclo de manipulación (Babiak y Hare, 2006; Pozueco, 2010).

6. La inteligencia de los psicópatas es un tema de enconado debate: algunos autores creen que son inteligentes (Cleckley, 1976), mientras que otros subrayan el matiz de no equiparar inteligencia académica con astucia "callejera", si bien parece ser que a mayor nivel intelectual, más habilidades de manipulación poseen (Pozueco, 2010).

Finalmente, es importante subrayar que muchas de las características delineadas y ampliamente descritas por Cleckley (1976) se centran en la ausencia de empatía, tales como: la falta de ansiedad, la pérdida o ausencia específica de intuición -del "darse cuenta" de que están errando, probablemente entorpecida por su afán incansable de egocentrismo- y un largo etcétera que desemboca en un pobre juicio moral y ético de sus propios actos. Curiosamente, los psicópatas son capaces de realizar juicios morales y éticos sobre las conductas de las demás personas, pero no sobre las suyas propias cuando éstas son negativas. En este sentido, como ya advirtiera Hare (1993), los psicópatas tienen sus propias "reglas" socio-morales, pero sólo las aplican a los demás.

\section{La empatía hacia las víctimas de diversos delitos según la percepción de los agresores y el rol de la psicopatía}

La empatía hacia la víctima es un constructo que se evalúa mediante el grado en que los individuos se identifican y empatizan con las víctimas de delitos (Rogstad, 2011). Las medidas de empatía hacia la víctima también evalúan indirectamente el nivel de la culpa atribuida a diferentes tipos de víctimas (Clements, Brannen, 
Kirkley, Gordon y Church, 2006). En los estudios con delincuentes, la evaluación de la empatía hacia la víctima suelen abarcar tanto la preocupación empática de los agresores como la toma de perspectiva hacia sus víctimas. Por lo general, estos estudios se centran en concretos delitos y víctimas, tales como las víctimas de violación, víctimas de acoso escolar y víctimas de abuso infantil (Ireland, 1999; Smith y Frieze, 2003).

Algunas investigaciones indican que la conducta antisocial se asocia con una escasa empatía hacia víctima. Por ejemplo, Woodworth y Porter (2002) especularon que el aumento de la tendencia de los delincuentes psicópatas hacia el homicidio instrumental se deriva de su insensibilidad y de la deficiente empatía hacia sus víctimas; sin embargo, todavía no hay datos empíricos que apoyen esta afirmación (Rogstad, 2011). Como ejemplo menos extremo, Ireland (1999) halló que los delincuentes que se involucraban en un comportamiento de acoso en prisión mostraban niveles más bajos de actitudes pro-víctimas en comparación con los internos no acosadores. Este resultado fue consistente en muestras de delincuentes, tanto en adultos como en jóvenes, si bien fue más pronunciado en los delincuentes juveniles. Además, los delincuentes que intimidaban a otros internos mostraban niveles más bajos tanto de toma de perspectiva como de preocupación empática en comparación con los delincuentes que fueron víctimas de acoso en la cárcel pero que nunca intimidaron a otros. De acuerdo con los resultados sobre la empatía general, las actitudes pro-víctimas y la empatía hacia las víctimas tienden a ser predictores de la conducta prosocial y pueden proporcionar un factor protector contra la conducta antisocial (Rogstad, 2011).

Sólo un estudio empírico ha examinado la concreta relación entre la empatía hacia la víctima y la psicopatía en adultos. En una pequeña muestra de 27 violadores y 27 delincuentes no sexuales, Fernández y Marshall (2003) investigaron la capacidad de la psicopatía para predecir empatía por las víctimas de violación. Sorprendentemente, los autores encontraron en los dos grupos que la psicopatía no era predictiva de empatía total hacia las víctimas de violación o de las puntuaciones en las subescalas de empatía hacia la violación -es decir, las víctimas de accidentes, las víctimas de agresión sexual y las propias víctimas de los violadores-. Sin embargo, las puntuaciones altas en el Factor 1 del PCL-R evidenciaron una asociación no significativa con los niveles más bajos de empatía hacia la víctima de las propias víctimas de los violadores -obteniendo un $r=-.32-$. Como ya admitieran los autores de este estudio, el mismo tiene una generalización limitada y sus resultados pueden haber sido influenciados por la baja prevalencia de la psicopatía.

Es evidente que la investigación futura necesita evaluar la específica relación entre la psicopatía y la empatía hacia las víctimas de delitos, en particular a la luz de las pruebas recientes de que los individuos psicópatas son expertos en la identificación de la vulnerabilidad -de los "puntos débiles" de los que habla Hare (1993) de las víctimas potenciales (Wheeler, Book y Costello, 2009).

\section{Psicopatía, ausencia de empatía y maltrato psicológico}

\section{Patrones de interacción coercitiva: Factores de riesgo hacia la insensibilidad y crueldad}

Algunas de las manifestaciones de maltrato psicológico más frecuentemente halladas en la investigación son las siguientes (Blázquez et al., 2009b, 2010; Moreno, Blázquez, García-Baamonde y Guerrero, 2011): humillaciones, descalificaciones o ridiculizaciones -tanto en público como en privado-, aislamiento social y económico, amenazas de maltrato a la víctima y/o a sus seres queridos, destrucción o daño a propiedades valoradas por la víctima -objetos o animales- y amenazas repetidas de divorcio o abandono. También lo son la negación de la violencia y la atribución de responsabilidad absoluta a la víctima de los episodios de maltrato. Por otra parte, la ausencia de empatía es una de las dimensiones afectivas más estudiadas y halladas en los estudios con agresores de pareja, y esta dimensión o componente es tan importante que, de hecho, «si un sujeto es capaz de empatizar y, por tanto, de experimentar las consecuencias de sus actos sobre los demás, será menos probable que dañe a otros y será más propenso a ayudarles» (Loinaz, Echeburúa y Ullate, 2012, p. 62).

Con objeto de evaluar el abuso psicológico en las relaciones íntimas de los estudiantes, Moreno et al. (2011) 
crearon un Cuestionario de Maltrato Psicológico -CMP-. Los resultados mostraron patrones coercitivos de interacción en las relaciones de noviazgo de los estudiantes, estando entre los IMP: la hostilidad, la culpabilización, la insistencia abusiva, la bondad aparente, la indiferencia y el menosprecio. Precisamente, todos estos patrones de interacción coercitiva también se han hallado en los estudios con psicópatas integrados y con los otros dos componentes de la TRÍOPE (Pozueco et al., 2013), todo lo cual satisfacción con la vida se asocia positivamente con relaciones felices (Arrindell, van Nieuwenhuizen y Luteijn, 2001).

En general, se observa que «a la psicopatía y al maquiavelismo no les va bien en el dominio interpersonal» (Ali y Chamorro-Premuzic, 2010b, p. 228). Según estos autores, la psicopatía está representada por un estilo de dominación interpersonal hostil que incluye formas sutiles de humillación, represalias e interacciones extremas proyectadas para inspirar miedo en los demás.

Los tres componentes de la TRÍOPE -psicopatía, maquiavelismo y narcisismo- generan relaciones infructuosas, tortuosas, caóticas, etc.; en suma, generan relaciones de pareja en riesgo (Pozueco y Moreno, 2013). Pero es la psicopatía subclínica el componente más peligroso y emocionalmente nocivo/tóxico de la TRÍOPE en las relaciones de pareja. Así, Williams, Spidel y Paulhus (2005) hallaron que los psicópatas subclínicos no sólo son más propensos a involucrarse en conductas sexuales de riesgo, sino también más propensos a utilizar tácticas coercitivas para obtener sexo, incluyendo el uso de drogas o actos de intimidación física o verbal. Esto último indica que los psicópatas utilizan el miedo y otras tácticas de manipulación y coerción para dominar y controlar a sus parejas. Según estos autores, la violencia que impregna la vida de los psicópatas parece extenderse a sus relaciones íntimas. La psicopatía subclínica también se asocia con varias actitudes y cogniciones que se consideran factores de riesgo de abuso psicológico que predisponen a la insensibilidad y crueldad con los demás. Por tanto, «las relaciones íntimas de los psicópatas parecen ser un ambiente peligroso para sus parejas, lleno de desapego, desconfianza y abuso» (Williams et al., 2005, pp. 5-6).

Sin duda alguna, «la ausencia de remordimientos, la ausencia de empatía y la insensibilidad son contraproducentes para el estatus, el enriquecimiento y el éxito de las relaciones íntimas» (Ullrich, Farrington y Coid 2008, p. 1169). Tener conciencia facilita el autocontrol y genera el sentimiento de responsabilidad, y también sirve para combatir los comportamientos inaceptables para el grupo. Pero, como ya hemos visto, los psicópatas no tienen conciencia (Hare, 1993), y tampoco tienen empatía (Cleckley, 1976), aspectos deficitarios que les facilitan el empleo de una violencia instrumental a través de la cual obtener sus fines mediante el uso de la manipulación y explotación de los demás.

\section{Una violencia instrumental basada en la manipulación y explotación}

La toma de perspectiva -empatía cognitiva- y la preocupación empática -empatía emocional- son los componentes más importantes de la empatía y los encargados de la comprensión emocional del otro y la respuesta congruente con dichas emociones (Loinaz, 2010). Aunque los psicópatas parecen tener empatía cognitiva pero fallan en empatía emocional (Pozueco y Moreno, 2013), la violencia instrumental que perpetran este tipo de agresores de pareja a través de diversas tácticas de manipulación y explotación de los demás sugiere que se trata de personas con una nula preocupación empática por sus víctimas.

Sin olvidar que la empatía es uno de los componentes del super-factor inteligencia emocional, la manipulación emocional fue denominada por Austin et al. (2007) como la "cara oscura" de la inteligencia emocional, operacionalizándola como la capacidad y/o habilidad de algunas personas para manipular las emociones de otras personas dentro de un entramado egoísta. Estos autores hallaron numerosas conductas de manipulación emocional en su estudio con sujetos maquiavélicos, y Grieve y Mahar (2010, p. 946) también han hallado lo mismo pero con sujetos diagnosticados de psicópatas a partir de muestras de estudiantes universitarios -posición general, psicópatas subclínicos-: «los psicópatas se caracterizan por conductas malévolas, manipuladoras, insensibles, engañosas y despiadadas -sin remordimientos-». 
Es muy relevante traer aquí a colación los estudios realizados sobre los tres componentes de la TRÍOPE, y no sólo sobre la psicopatía subclínica. Aunque el maquiavelismo, el narcisismo y la psicopatía son constructos diferentes (Paulhus y Williams, 2002), existe una copiosa y actualizada evidencia de que los tres tienen en común dos rasgos importantes: el empleo de tácticas de explotación y manipulación en sus interacciones y una ausencia de empatía hacia los demás (Black, 2013; Holtzman, 2011; Jonason, Li y Teicher, 2010; Rauthmann, 2012). Las personas caracterizadas por los rasgos de la TRÍOPE son capaces de aprovecharse de los demás (McHoskey, 2001), de obtener mediante la extorsión y con éxito -sin siquiera ser denunciados- los recursos de los demás (Campbell, Bush, Brunell y Shelton, 2005) y, en algunos casos, de cometer delitos (Neumann y Hare, 2008).

Para los psicópatas integrados, y también para los otros dos componentes de la TRÍOPE, el amor tiene un lado oscuro. Algunas de estas personas son impulsivas y prefieren beneficios a corto que a largo plazo. Por ejemplo, algunos suelen emplear una estrategia de emparejamiento a corto plazo, donde permanecen con parejas sexuales durante un breve periodo antes de dejarlas, con lo que podría decirse que esta estrategia les permite obtener el máximo de recursos de un compañero íntimo sin necesidad de invertir tiempo ni de establecer un compromiso emocional (Jonason y Kavanagh, 2010), no importándoles en absoluto si las parejas/víctimas se sienten mal tras saberse utilizadas y explotadas para tales fines y habiéndoles realizado promesas de una relación de pareja de ensueño.

Además de su inclinación por relaciones de explotación a corto plazo, los TRÍOPES son conocedores de una serie de tácticas para manipular y explotar a los demás. Por ejemplo, Jonason y Webster (2012) encontraron que los TRÍOPES son egoístas, competitivos y estrategas en sus estrategias activas de manipulación. En concreto, utilizan la influencia social para manipular y explotar a los demás y se cree que poseen una serie de tácticas abusivas propias a su disposición. Por ejemplo, las altas puntuaciones en los tres instrumentos que miden los componentes de la TRÍOPE correlacionan con el uso de encanto o "hacerse el/la interesante y/o el/la difícil" para manipular a los demás. Asimismo, los métodos específicos de influencia correlacionaron individualmente con cada uno de los tres componentes de la TRÍOPE. La psicopatía correlacionó con el uso de encanto y la coacción, el maquiavelismo correlacionó con el uso de encanto y seducción, y el narcisismo correlacionó con invocar sentimientos de responsabilidad en otros. Además, este estudio encontró que cada uno de los componentes de la TRÍOPE correlacionaba con el uso de los mismos tipos de tácticas de influencia, independientemente de la persona/víctima objetivo, lo que sugiere que no adaptan su método de manipulación para ajustarse a su objetivo/víctima. Esta investigación sugiere que los particulares rasgos de los TRÍOPES les caracterizan por una serie de habilidades específicas que aplican a través de una variedad de tácticas de manipulación y explotación. Sin duda alguna, los TRÍOPES utilizarán todos los medios necesarios para lograr su objetivo, ya que ven a los demás como instrumentos o cosas a utilizar-cosificación-para colmar sus necesidades (Jonason y Webster, 2012).

\section{Discusión}

"Simpático", "encantador", "inteligente”, “despierto", "que causa impresión”, "que inspira confianza” y "un gran éxito con las/os mujeres/hombres". Éstas son algunas de las descripciones repetidamente empleadas por Cleckley (1976) en sus estudios de casos sobre psicópatas. Pero los y las psicópatas son también, por supuesto, "irresponsables", "autodestructivos", etc. Estas descripciones ponen de relieve las grandes frustraciones, inquietudes y enigmas que rodean el estudio de la psicopatía (Pozueco y Moreno, 2013). El perfil psicosocial del psicópata integrado o subclínico es fácil de establecer; lo que no resulta tan sencillo es identificarlos, y menos con la técnica del "a ojo de buen cubero" y sin utilizar las herramientas adecuadas que actualmente han sido validadas a nivel internacional.

Sabemos, pues, cómo son los psicópatas, y algunos autores sugieren que hasta podemos intuir cómo les gusta ir disfrazados -«serpientes vestidas de traje»- (Babiak y Hare, 2006). Los psicópatas intentan aparentar lo que 
no son; por eso es habitual que su apariencia sea normal y hasta afable. No dan muestras de ansiedad o de sentimientos de culpa. Obviamente, no son personas de las que te puedas fiar. No es nada extraño que den muestras continuas de egocentrismo: parece como si su frase preferida fuese "yo, yo, yo, y después... yo" (Pozueco, 2010). Son incapaces de generar una relación duradera y genuina de amistad, de amor, etc., y resulta inútil castigarlos con ánimo de enseñarles -de que aprendan- porque no entienden -o hacen como que no entiendennada de lo que ataña a la justicia. No sirven como ejemplo del buen funcionamiento de sus emociones, entre otras cosas, porque se caracterizan por su ausencia total de empatía. Son incapaces de prever el impacto de su conducta sobre los demás; no se enteran de nada, o más bien, hacen como que no se enteran. Por último, algunos -no todos- son incapaces de planificar de cara al futuro.

Es muy importante conocer el perfil psicosocial y el estilo de vida de estos sujetos para poder identificarlos y evitar que causen daños innecesarios. Pero es más importante todavía darse cuenta de que, para ellos, el mundo no se divide entre ellos y los demás, sino simplemente en lo que les afecta exclusivamente a ellos de una manera u otra. Hasta ahora, la ciencia nos demuestra que es estéril tratar de convertir a los psicópatas en personas normales, por el hecho sencillo de que no están debidamente conectados con el resto, de que no son realmente sociables aunque lo aparenten, de que de sus actos no dependen el que los demás vivan más tranquilos sino peor. Aunque resulte sarcástico, parece que algo sí tenemos que agradecerles a los psicópatas, y es habernos enseñado que sirve de muy poco intentar evitar el mal por el mal, en el sentido de la crueldad; lo importante, como sugiere Baron-Cohen (2011), es inundar el mundo de empatía, que es justamente lo que ellos no tienen.

Los dos componentes de la empatía son claves para entender parte del funcionamiento interaccional y estilo de vida de los psicópatas. Sabemos que estos sujetos tienen emociones poco profundas y generalmente superficiales, y es por ello que presentan una serie de déficits en empatía emocional que les impiden tomar la perspectiva de los demás desde el punto de vista afectivo, no sabiendo -o no queriendo- ponerse en el lugar de los demás más que en un plano meramente intelectual, y por eso se cree que los psicópatas sólo disponen de empatía cognitiva.

No obstante, por más que el psicópata sepa fingir o imitar algunos sentimientos genuinamente humanos -al conocerlos a nivel meramente cognitivo, intelectual-, lo cierto es que frecuentemente será incapaz de describir la subjetividad -las connotaciones subjetivas- de los distintos estados afectivos, y si lo hace será "de parrafada", "de guión” (Pozueco, 2010), porque, como ya establecieran muy gráficamente Johns y Quay, «los psicópatas se saben la letra, pero no la música» de las emociones (Johns y Quay, 1962, p. 217). La conclusión que puede extraerse de esta gráfica frase es que «estas personas pueden captar activamente el concepto de emoción, pero podrían no ser capaces de utilizar los componentes afectivos de la empatía para guiar su comportamiento» (Mullins-Nelson et al., 2006, p. 145). Es decir, los psicópatas saben lo que tienen que decir y/o lo que los demás quieren oír -lo que sería parte del componente cognitivo de la empatía-, pero no lo sienten en absoluto -que sería parte del componente emocional-afectivo de la empatía-. Dicho de otro modo, este tipo de personas sienten emociones sólo de lo más superficiales y a nivel meramente intelectual.

En el caso de la psicopatía, el moderno concepto de empatía cero negativa sería sólo aplicable en la vertiente emocional de la empatía, pero no en la cognitiva. Los déficits afectivos -tales como experiencia emocional superficial, falta de remordimiento y no aceptar la responsabilidad de las acciones de uno mismo- son comúnmente considerados el sello distintivo del síndrome psicopático o perfil de personalidad psicopática. Tal vez lo más notable es que los psicópatas prototípicos muestran una total indiferencia por la experiencia emocional de los demás, lo que -y sólo en algunos casos- puede disponerles a cometer crímenes incomprensibles y particularmente violentos (Blair, 1995, 2007). Sin embargo, no está claro si estos déficits afectivos -fundamentalmente en empatía- son específicos de la psicopatía o también están presentes en el heterogéneo grupo de los delincuentes antisociales en general (Rogstad, 2011).

Los resultados actuales empiezan a aclarar la evidencia existente sobre la relación de la psicopatía con disminuciones de la empatía afectiva, pero no de la empatía cognitiva (Blair, 2005, 2007; Smith, 2006). En con- 
creto, la propensión de los psicópatas a la violencia supuestamente refleja una incapacidad de regular la conducta que daña a los demás. Verdadera y correctamente socializados, los sujetos no psicópatas inhiben el comportamiento agresivo en virtud de la empatía afectiva, es decir, cuando vicariamente experimentan las emociones negativas inducidas - por ejemplo, el miedo, la angustia- de otra persona (Blair, 1995, 2005). De acuerdo con esta hipótesis, los delincuentes psicópatas y los delincuentes con TAP del estudio de Rogstad (2011) mostraron niveles sustancialmente menores de preocupación empática que los delincuentes no psicópatas, si bien, como admite la misma autora de este estudio, «el papel del TAP en estas diferencias no fue concluyente» (Rogstad, 2011, p. 85).

Por otro lado, hemos visto cómo los psicópatas se caracterizan por perpetrar, fundamentalmente, un tipo de violencia psicológica en sus relaciones de pareja y caracterizada por diversas tácticas de manipulación y explotación, modus operandi que también se extiende a otros contextos, situaciones y/o relaciones por los que pululan estos sujetos. La agresión indirecta, instrumental y/o encubierta es la que mayormente emplean los psicópatas integrados en sus relaciones de pareja, y sólo se decantan por la agresión manifiesta, física, cuando perciben que sus tretas encubiertas no surten los efectos que preveían (Pozueco, 2010). Por tanto, en las relaciones íntimas, los psicópatas perpetran un maltrato psicológico caracterizado específicamente por una violencia instrumental o premeditada, es decir, dirigida, generalmente, a obtener un fin: dinero, sexo, estatus, etc.

Finalizamos esta revisión con algunos apuntes para la prevención de la violencia, en general, y de la violencia psicológica, en particular, respecto a las relaciones de pareja. Por un lado, hay que recordar que «la empatía tiene un gran peso en el ámbito rehabilitador», hasta el punto de que «su mejora es un componente central en los programas diseñados para intervenir con agresores» (Loinaz et al., 2012, p. 63), independientemente del perfil diferencial de los diversos tipos de agresores de pareja (Loinaz y Echeburúa, 2010).

Por otro lado, lo dicho antes no es posible en el caso de los agresores psicópatas, ya agredan en el ámbito de las relaciones de pareja o en cualquier otro ámbito. Hasta la fecha de hoy, y como se viene sosteniendo desde antaño, el paisaje con respecto al tratamiento de la psicopatía en general es desolador y descorazonador (Hare, 1993), hasta el punto de que se sugiere que es estéril tratar de enseñarles a los psicópatas a ser empáticos, siendo mucho más productivo incidir en las consecuencias de sus actos y tomando como referencia ese egocentrismo tan característico de los mismos (Wong y Hare, 2005). El problema de esta sugerencia es que si tratas de manipular a un experto manipulador, puede que al final uno salga más escaldado de lo que quizá piense (Pozueco, 2010).

A pesar de este panorama tan pesimista, también hay que subrayar el hecho de que «distintos estudios han propuesto que la ineficacia de algunas intervenciones [con agresores de pareja en general] se deben, en parte, a no prestar atención a las necesidades terapéuticas específicas de los agresores y a utilizar únicamente programas homogéneos y estandarizados» (Loinaz y Echeburúa, 2010, p. 93).

Sin duda alguna, en el caso de los agresores psicópatas se hace necesario seguir investigando sobre sus necesidades terapéuticas específicas, y puede que, aunque hasta la fecha no haya resultados convincentes, el entrenamiento en varios factores de la inteligencia emocional -y la empatía es uno de los más centrales-, combinado con algunas de las peculiares características psicopáticas, podrían al menos enseñarnos qué es en lo que tendríamos que fijarnos en estos sujetos para extraer conclusiones y empezar a diseñar directrices de prevención primaria que nos vendrían bien a toda la sociedad.

\section{Referencias}

Ali, F., Amorim, I. S. y Chamorro-Premuzic, T. (2009). Empathy deficits and trait emotional intelligence in psychopathy and Machiavellianism. Personality and Individual Differences, 47, 758-762.

Ali, F. y Chamorro-Premuzic, T. (2010a). Investigating Theory of Mind deficits in nonclinical psychopathy and Machiavellianism. Personality and Individual Differences, 49, 169-174. 
Ali, F. y Chamorro-Premuzic, T. (2010b). The dark side of love and life satisfaction: Associations with intimate relationships, psychopathy and Machiavellianism. Personality and Individual Differences, 48(2), 228-233.

Amor, P. J., Echeburúa, E., y Loinaz, I. (2009). ¿Se puede establecer una clasificación tipológica de los hombres violentos contra su pareja? International Journal of Clinical and Health Psychology, 9(3), 519-539.

Andrew, J., Cooke, M. y Muncer, S. (2008). The relationship between empathy and Machiavellianism: An alternative to empathizing-systemizing theory. Personality and Individual Differences, 44, 1203-1211.

Arce, R., Fariña, F., Carballal, A. y Novo, M. (2009). Creación y validación de un protocolo de evaluación forense de las secuelas psicológicas de la violencia de género. Psicothema, 21(2), 241-247.

Arrindell, W. A., van Nieuwenhuizen, C. y Luteijn, F. (2001). Chronic psychiatric status and satisfaction with life. Personality and Individual Differences, 31, 145-155.

Asensi, L. (2008). La prueba pericial psicológica en asuntos de violencia de género. Revista Internauta de Práctica Jurídica, 21, 15-29.

Austin, E. J., Farrelly, D., Black, C. y Moore, H. (2007). Emotional intelligence, Machiavellianism and emotional manipulation: Does EI have a dark side? Personality and Individual Differences, 43, 179-189.

Babiak, P. y Hare, R. D. (2006). Snakes in suits: When psychopaths go to work. New York, NY: Regan Books. Baron-Cohen, S. (2011). Zero degrees of empathy: A new theory of human cruelty. London, UK: Allen Lane.

Baron-Cohen, S., Wheelwright, S., Hill, J.J., Raste, Y. y Plumb, I. (2001). The "Reading the Mind in the Eyes" test revised version: A study with normal adults, and adults with Asperger syndrome or high functioning autism. Journal of Child Psychology and Psychiatry, 42, 241-251.

Benning, S. D., Patrick, C. J., Blonigen, D. M., Hicks, B. M. y Iacono, W. G. (2005). Estimating facets of psychopathy from normal personality traits: A step toward community epidemiological investigations. Assessment, 12(1), 3-18.

Black, P. J. (2013). The dark triad and interpersonal assessment of vulnerability: Cues used and accuracy. Okanagan, Canadá: The Faculty of Graduate Studies, University of British Columbia. (Tesis de Máster no publicada).

Blair, R. J. R. (1995). A cognitive developmental approach to morality: Investigating the psychopath. Cognition, 57, 1-29.

Blair, R. J. R. (2005). Responding to the emotions of others: Dissociating forms of empathy through the study of typical and psychiatric populations. Consciousness and Cognition, 14, 698-718.

Blair, R. J. R. (2007). Empathic dysfunction in psychopathic individuals. En T.F.D. Farrow y P.W.R. Woodruff (Eds.), Empathy in mental illness (pp. 3-16). Cambridge, UK: Cambridge University Press.

Blázquez, M. y Moreno, J. M. (2008a). Análisis de la inteligencia emocional en la violencia de género. Revista Electrónica de Investigación Psicoeducativa, 6(2), 475-500.

Blázquez, M. y Moreno, J. M. (2008b). Maltrato psicológico en la pareja: Prevención y educación emocional. Madrid: EOS Psicología Jurídica.

Blázquez, M., Moreno, J. M. y García-Baamonde, Mª E. (2009a). Estudio del maltrato psicológico, en las relaciones de pareja, en jóvenes universitarios. Electronic Journal of Research in Educational Psychology, 7(2), 691-714.

Blázquez, M., Moreno, J. M. y García-Baamonde, Ma . E. (2009b). Inteligencia emocional como alternativa para la prevención del maltrato psicológico en la pareja. Anales de Psicología, 25(2), 250-260.

Blázquez, M., Moreno, J. M. y García-Baamonde, Ma . E. (2010). Revisión teórica del maltrato psicológico en la violencia conyugal. Psicología y salud, 20(1), 65-75.

Bowen, E., Gilchrist, E., y Beech, A. R. (2008). Change in treatment has no relationship with subsequent reoffending in U.K. domestic violence sample: A preliminary study. International Journal of Offender Therapy and Comparative Criminology, 52, 598-614.

Campbell, W., Bush, C., Brunell, A. B. y Shelton, J. (2005). Understanding the social costs of narcissism: The case of the tragedy of the commons. Personality and Social Psychology Bulletin, 31, 1358-1368. 
Cavanaugh, M. M., y Gelles, R. J. (2005). The utility of male domestic violence offender typologies: New directions for research, policy and practice. Journal of Interpersonal Violence, 20, 155-166.

Cleckley, H. M. (1976). The mask of sanity: An attempt to clarify the so-called psychopathic personality (5 ${ }^{\text {th }}$ ed.). St. Louis, MO: C.V. Mosby.

Clements, C., Brannen, D., Kirkley, S., Gordon, T. y Church, W. (2006). The measurement of concern about victims: Empathy, victim advocacy and the Victim Concern Scale (VCS). Legal and Criminological Psychology, 11, 283-295.

Cooke, D. J., Michie, C. y Hart, S. D. (2006). Facets of clinical psychopathy: Toward clearer measurement. En C.J. Patrick (Ed.), Handbook of psychopathy (pp. 91-106). New York, NY: Guilford Press.

Dutton, D. G. (2006). Rethinking domestic violence. Vancouver, Canadá: University of British Columbia Press. Echeburúa, E., Amor, P. J., Loinaz, I., y De Corral, P. (2010). Escala de Predicción del Riesgo de Violencia Grave contra la Pareja -Revisada- (EPV-R). Psicothema, 22, 1054-1060.

Echeburúa, E. y Fernández-Montalvo, J. (2007). Male batterers with and without psychopathy: A study in the prisons of Spain. International Journal of Offender Therapy and Comparative Criminology, 51, 254-263.

Edens, J. F., Marcus, D. K., Lilienfeld, S. O. y Poythress, N. G. J. (2006). Psychopathic, not psychopath: Taxometric evidence for the dimensional structure of psychopathy. Journal of Abnormal Psychology, 115, 131-144.

Fariña, F., Arce, R., y Buela-Casal, G. (Eds.) (2009). Violencia de género: Tratado psicológico y legal. Madrid: Biblioteca Nueva.

Fehr, B., Samsom, D. y Paulhus, D. L. (1992). The construct of Machiavellianism: Twenty years later. En C.D. Spielberger y J .N. Butcher (Eds.), Advances in personality assessment (Vol. 9) (pp. 77-116). Hillsdale, NJ: LEA.

Fernández, Y. M. y Marshall, W. L. (2003). Victim empathy, social self-esteem, and psychopathy in rapists. Sexual Abuse: Journal of Research \& Treatment, 15, 11-26.

Frick, P. J. y Moffitt, T. E. (2010). A Proposal to the DSM-V Childhood Disorders and the ADHD and Disruptive Behavior Disorders Work Groups to include a specifier to the diagnosis of Conduct Disorder based on the presence of callous-unemotional traits. Washington, DC: APA.

Garrido, V. J. (1994). El psicópata como entidad psicológica y cultural. En E. Echeburúa (Dir.), Personalidades violentas (pp. 67-80). Madrid: Pirámide.

Grieve, R. y Mahar, D. P. (2010). The emotional manipulation-psychopathy nexus. Relationships with emotional intelligence, alexithymia, and ethical position. Personality and Individual Differences, 48(8), 945-950.

Guay, J. P., Ruscio, J., Knight, R. A. y Hare, R. D. (2007). A taxometric analysis of the latent structure of psychopathy: Evidence for dimensionality. Journal of Abnormal Psychology, 116, 701-716.

Habel, U., Kuhn, E., Salloum, J. B., Devos, H. y Schneider, F. (2002). Emotional processing in psychopathic personality. Aggressive Behavior, 28, 394-400.

Hall, J. R. y Benning, S. D. (2006). The "successful" psychopath: Adaptative and subclinical manifestation of psychopathy in the general population. En C.J. Patrick (Ed.), Handbook of psychopathy (pp. 459-478). New York, NY: Guilford Press.

Hare, R. D. (1993). Without conscience: The disturbing world of the psychopaths among us. New York, NY: Pocket Books.

Hare, R .D. (2003). Manual for the Hare Psychopathy Checklist-Revised (PCL-R): $2^{\text {nd }}$ Edition. Toronto, ON: MHS.

Hare, R.D., Hart, S.D. y Harpur, T.J. (1991). Psychopathy and the DSM-IV criteria for antisocial personality disorder. Journal of Abnormal Psychology, 100, 391-398.

Holtzman, N. S. (2011). Facing a psychopath: Detecting the Dark Triad of personality from emotionally-neutral faces, using prototypes from the Personality Faceaurus. Journal of Research in Personality, 45, 648-654.

Holtzworth-Munroe, A., y Stuart, G. L. (1994). Typologies of male batterers: Three subtypes and the differences among them. Psychological Bulletin, 116, 476-497. 
Holtzworth-Munroe, A., Meehan, J.C., Herron, K., Rehman, U., y Stuart, G.L. (2000). Testing the HoltzworthMunroe and Stuart (1994) batterer typology. Journal of Consulting and Clinical Psychology, 68, 10001019.

Huss, M. T. y Langhinrichsen-Rohling, J. (2000). Identification of the psychopathic batterer: The clinical, legal, and policy implications. Aggression and Violent Behavior, 5, 403-422.

Huss, M. T. y Langhinrichsen-Rohling, J. (2006). Assessing the generalization of psychopathy in a clinical sample of domestic violence perpetrators. Law and Human Behavior, 30, 571-586.

Ireland, J. L. (1999). Provictim attitudes and empathy in relation to bullying behaviour among prisoners. Legal and Criminological Psychology, 4, 51-66.

Jolliffe, D. y Farrington, D. P. (2004). Empathy and offending: A systematic review and meta-analysis. Aggression and Violent Behavior, 9, 441-476.

Johns, J. H. y Quay, H. C. (1962). The effect of social reward on verbal conditioning in psychopathic and neurotic military offenders. Journal of Consulting Psychology, 26(3), 217-220.

Jonason, P. K. y Kavanagh, P. (2010). The dark side of love: Love styles and the Dark Triad. Personality and Individual Differences, 49, 606-610.

Jonason, P. K., Li, N. P. y Teicher, E. A. (2010). Who is James Bond? The Dark Triad as an agentic social style. Individual Differences Research, 8, 111-120.

Jonason, P. K., Valentine, K. A., Li, N. P. y Harbeson, C.L. (2011). Mate-selection and the Dark Triad: Facilitating a short-term mating strategy and creating a volatile environment. Personality and Individual Differences, 51, 759-763.

Jonason, P. K. y Webster, G. D. (2012). A protean approach to social influence: Dark Triad personalities and social influence tactics. Personality and Individual Differences, 52, 521-526.

Kirsch, L. G. y Becker, J. V. (2007). Emotional deficits in psychopathy and sexual sadism: Implications for violent and sadistic behavior. Clinical Psychology Review, 27, 904-922.

Kosson, D. S., Suchy, Y., Mayer, A. R. y Libby, J. (2002). Facial affect recognition in criminal psychopaths. Emotion, 2, 398-411.

Kotov, R., Ruggero, C. J., Krueger, R.F., Watson, D., Yuan, Q. y Zimmerman, M. (2011). New dimensions in the quantitative classification of mental illness. Archives of General Psychiatry, 68, 1003-1011.

Lawrence, E., Shaw, P., Baker, D., Baron-Cohen, S. y David, A. (2004). Measuring empathy: Reliability and validity of the Empathy Quotient. Psychological Medicine, 34, 911-919.

Lee, K. y Ashton, M. C. (2005). Psychopathy, Machiavellianism, and narcissism in the five-factor model and the HEXACO model of personality structure. Personality and Individual Differences, 38, 1571-1582.

Loinaz, I. (2010). Estudio de las tipologías de agresores de pareja en centros penitenciarios: Estudio validativo. Barcelona: Centre d'Estudis Jurídics i Formació Especialitzada, Departament de Justicia, Generalitat de Catalunya.

Loinaz, I. y Echeburúa, E. (2010). Necesidades terapéuticas en agresores contra la pareja según su perfil diferencial. Clínica Contemporánea, 1, 85-95.

Loinaz, I., Echeburúa, E., Ortiz-Tallo, M. y Amor, P.J. (2012). Propiedades psicométricas de la Conflict Tactics Scales (CTS-2) en una muestra española de agresores de pareja. Psicothema, 24, 142-148.

Loinaz, I., Echeburúa, E. y Torrubia, R. (2010). Tipologías de agresores contra la pareja. Psicothema, 22, 106111.

Loinaz, I., Echeburúa, E. y Ullate, Mª (2012). Estilo de apego, empatía y autoestima en agresores de pareja. Terapia Psicológica, 30(2), 61-70.

Lynam, D. R. y Derefinko, K. J. (2006). Psychopathy and personality. En C.J. Patrick (Ed.), Handbook of psychopathy (pp. 133-155). New York, NY: Guilford Press.

Lynam, D. R. y Vachon, D. D. (2012). Antisocial personality disorder in DSM-5: Missteps and missed opportunities. Personality Disorders, 3, 483-495. 
Mahmut, M. K., Homewood, J. y Stevenson, R. J. (2008). The characteristics of noncriminals with high psychopathy traits: Are they similar to criminal psychopaths? Journal of Research in Personality, 42, 679692.

Malterer, M. B., Lilienfeld, S. O., Neumann, C. S. y Newman, J. P. (2010). Concurrent validity of the psychopathic personality inventory with offender and community samples. Assessment, 17, 3-15.

Marietán, H. R. (2011). No son psicópatas, pero lo parecen. ALCMEÓN, Revista Argentina de Clínica Neuropsiquiátrica, 17(1), 74-93.

Marsh, A. A. (2013). What can we learn about emotion by studying psychopathy? Frontiers in Human Neuroscience, 7, 1-13.

McCord, W. M. y McCord, J. (1964). The psychopath: An essay on the criminal mind. Princeton, NJ: Van Nostrand.

McHoskey, J. W. (2001). Machiavellianism and personality dysfunction. Personality and Individual Differences, 31, 791-798.

McHoskey, J. W., Worzel, W. y Szyarto, C. (1998). Machiavellianism and psychopathy. Journal of Personality and Social Psychology, 74, 192-210.

Moreno, J. M., Blázquez, M., García-Baamonde, Ma. E. y Guerrero, E. (2011). Psychological abuse in young couples: Risk factors. Journal of Social Service Research, 37, 555-570.

Mullins-Nelson, J. L., Salekin, R. T. y Leistico, A-M. R. (2006). Psychopathy, empathy, and perspective-taking ability in a community sample: Implications for the successful psychopathy concept. International Journal of Forensic Mental Health, 5, 133-149.

Neumann, C. S. y Hare, R.D. (2008). Psychopathic traits in a large community sample: Links to violence, alcohol use, and intelligence. Journal of Consulting and Clinical Psychology, 76, 893-899.

Paal, T. y Bereczkei, T. (2007). Adult theory of mind, cooperation, Machiavellianism: The effect of mindreading on social relations. Personality and Individual Differences, 43, 541-551.

Paulhus, D. L. y Williams, K. M. (2002). The dark triad of personality: Narcissism, machiavellianism, and psychopathy. Journal of Research in Personality, 36, 556-563.

Pozueco, J. M. (2010). Psicópatas integrados: Perfil psicológico y personalidad. Madrid: EOS Psicología Jurídica.

Pozueco, J. M. (2011). Psicopatía, trastorno mental y crimen violento: Aspectos clínico-forenses, médico-legales y criminológicos. Madrid: EOS Psicología Jurídica.

Pozueco, J. M. y Moreno, J. M. (2013). La tríada oscura de la personalidad en las relaciones íntimas: Psicopatía, maquiavelismo, narcisismo y maltrato psicológico. Boletín de Psicología, 107, 91-111.

Pozueco, J. M., Moreno, J. M., Blázquez, M. y García-Baamonde, Mª . E. (2013). Psicópatas integrados/subclínicos en las relaciones de pareja: Perfil, maltrato psicológico y factores de riesgo. Papeles del Psicólogo, 34 , $32-48$.

Pozueco, J. M., Moreno, J. M., Blázquez, M. y García-Baamonde, Mª . E. (en prensa). El maltratador psicópata: Un perfil no psicopatológico. Anales de Psicología.

Pozueco, J. M., Romero, S. L. y Casas, N. (2011). Psicopatía, violencia y criminalidad: Un análisis psicológico-forense, psiquiátrico-legal y criminológico (Parte II). Cuadernos de Medicina Forense, 17(4), 175-192.

Raine, A. y Sanmartín, J. (2000). Violencia y psicopatía. Barcelona: Ariel.

Rauthmann, J. F. (2012). The Dark Triad and interpersonal perception: Similarities and differences in the social consequences of narcissism, Machiavellianism, and psychopathy. Social Psychological and Personality Science, 3, 487-496.

Richell, R. A., Mitchell, D. G. V., Newman, C., Leonard, A., Baron-Cohen, S. y Blair, R. J. R. (2003). Theory of mind and psychopathy: Can psychopathic individuals read the 'language of the eyes'? Neuropsychologia, 41, 523-526.

Rogstad, J. E. (2011). Psychopathy and antisocial personality disorder: Gender differences in empathy and 
alexithymia. Denton, TX: Department of Psychology, University of North Texas. (Tesis de Máster no publicada).

Skeem, J. L. y Cooke, D. J. (2010). Is criminal behavior a central component of psychopathy?: Conceptual directions for resolving the debate. Psychological Assessment, 22, 433-445.

Skodol, A. E., Clark, L. A., Bender, D. S., Krueger, R. F., Morey, L. C., Verheul, R. ... Oldham, J. M. (2011). Proposed changes in personality and personality disorder assessment and diagnosis for DSM-5 Part I: Description and rationale. Personality Disorders. 2(1), 4-22.

Smith, C. A. y Frieze, I. H. (2003). Examining rape empathy from the perspective of the victim and the assailant. Journal of Applied Social Psychology, 33, 476-498.

Smith, A. (2006). Cognitive empathy and emotional empathy in human behaviour and evolution. The Psychological Record, 56, 3-21.

Spidel, A., Vincent, G., Huss, M. T., Winters, J., Thomas, L. y Dutton, D. G. (2007). Psychopathy: Subtyping perpetrators of domestic violence. En H.F. Hervé y J.C. Yuille (Eds.), The psychopath: Theory, research, and practice (pp. 327-342). Mahwah, NJ: LEA.

Taverniers, K. (2001). Abuso emocional en parejas heterosexuales. Revista Argentina de Sexualidad Humana, 15, 28-34.

Ullrich, S., Farrington, D. P. y Coid, J. W. (2008). Psychopathic personality traits and life-success. Personality and Individual Differences, 44, 1162-1171.

Vallés, A. y Vallés, C. (2000). Inteligencia emocional: Aplicaciones educativas. Madrid: EOS.

Vernon, P. A., Villani, C. V., Vickers, L. C. y Harris, J. A. (2008). A behavioral genetic investigation of the Dark Triad and the Big 5. Personality and Individual Differences, 44, 445-452.

Walker, L. E. A. (2000). The battered woman syndrome. New York, NY: Springer Publishing Company.

Wastell, C. y Booth, A. (2003). Machiavellianism: An alexithymic perspective. Journal of Social \& Clinical Psychology, 22, 730-744.

Wheeler, S., Book, A. y Costello, K. (2009). Psychopathic traits and perceptions of victim vulnerability. Criminal Justice and Behavior, 36, 635-648.

Williams, K. M., Spidel, A. y Paulhus, D. L. (2005). "Sex, lies, and more lies: Exploring the intimate relationships of subclinical psychopaths". Ponencia presentada en la Conference of the Society for the Scientific Study of Psychopathy. Vancouver, BC, Canada, Julio de 2005.

Wong, S. C. P. y Hare, R. D. (2005). Program guidelines for the institutional treatment of violent psychopaths. Toronto, ON: MHS.

Woodworth, M. y Porter, S. (2002). In cold blood: Characteristics of criminal homicides as a function of psychopathy. Journal of Abnormal Psychology, 111, 436-445.

Manuscrito recibido: 02/07/2013

Revisión recibida: 07/10/2013

Manuscrito aceptado: 09/10/2013 